\title{
From medical school to medical practice: a national tracking system to underpin planning for a sustainable medical workforce in Australasia
}

\author{
John S Humphreys, David Prideaux, Justin J Beilby and Nicholas J Glasgow \\ To provide the ongoing robust evidence needed for workforce planning, \\ a national longitudinal study will itself need to be sustained into the future
}

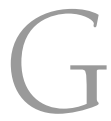
lobally, medical workforce shortages and maldistribution - are major impediments to providing accessible, sustainable and safe health care. ${ }^{1,2}$ Strategic medical workforce planning is essential for resolving this problem. This requires up-todate, robust data to predict future trends and, most importantly, give sound insights into the underlying determinants of workforce patterns and choices for workforce participation. Many countries have sought to develop appropriate medical workforce data collection mechanisms for tracking practitioners from graduation through employment, with varying degrees of success. ${ }^{3,4}$ Rural medical workforce shortages have been the impetus for several of these collections. Experience from these highlights the importance of comprehensive, systematic and ongoing quantitative data collection, and the value of establishing a minimum data collection system from the outset of a medical education program. ${ }^{5-9}$

In Australia and New Zealand, a small number of cross-sectional workforce studies have been undertaken in the past. ${ }^{10} \mathrm{~A}$ major limitation in using the disparate research outcomes of these to inform policy directions is the lack of connection between studies of students, current practitioners and past practitioners. Evaluations of government health workforce initiatives in Australia and New Zealand further emphasise the need for a uniform data collection methodology as the basis for tracking the progress of students throughout their training program and beyond. ${ }^{11-13}$

All of these approaches highlight the fundamental problem - a series of cross-sectional studies and evaluations "stitched together" to answer workforce questions will always provide less robust evidence than a well conducted, purpose-built, ongoing study. Sound medical workforce planning requires longitudinal data. Responding to this need, Medical Deans Australia and New Zealand (MDANZ) established the Medical Schools Outcomes Database (MSOD) and Longitudinal Tracking Project in 2005. This project collects reliable demographic and educational data about medical students across all Australian and New Zealand medical schools.

To date, data have been collected on at least 11200 medical students in Australia over 5 years of their training. Using an agreed national minimum dataset based on consistent definitions, the project targets critical times of medical career decision making at the commencement of, and exit from, medical school; during the intern year; and during postgraduate training. Demographic information and data on vocational and practice location intentions are collected from surveys of students commencing medical school. Data obtained directly from the medical schools provide information on the nature of the students' education and clinical experiences; for example, the length and nature of rural exposure, or membership of rural health clubs. Exit surveys of students again collect demographic data, vocational and practice location inten- tions, data on factors influencing career choices, and future contact details.

Initial results from the MSOD show that length of residence in a rural area, generalist practice intention, and financially supported study (but not a bonded arrangement) are the strongest predictors of intention to take up rural medical practice. In addition, changing trends towards intended take-up of specialties are apparent - for example, a steadily increasing proportion of students intending to take up general practice was apparent between 2006 and 2008. ${ }^{14}$ In short, excellent data now exist to benchmark the impact of medical education and training activities.

Success for this project requires more than a strong interest in evaluative medical education research. Other important catalysts have included champions (leading medical education researchers and medical school deans), resources (national funding provided by the Australian Government), a mandate (national auspicing by MDANZ to ensure comprehensive collection of relevant data), and timing (eg, to assess the impact and effectiveness of specific Rural Undergraduate Support and Coordination program funding designed to increase the numbers of students taking up rural practice). Importantly, the process for establishing the MSOD drew on international expertise to identify possible pitfalls and to help realise its potential. Professor Howard Rabinowitz, a rural workforce expert in the United States who played a leading role in a medical school longitudinal study in Pennsylvania, was engaged in an advisory capacity at the outset and continues to have an ongoing role.

The MSOD will allow both short- and long-term monitoring and reporting on outcomes of medical education programs, and will inform national workforce policy implementation. It can contribute to evaluating the effectiveness of federally funded medical education initiatives in achieving improved medical workforce recruitment and retention. It complements activities of bodies such as the National Health Workforce Taskforce (NHWT), state and territory medical boards in Australia, and the Medical Council of New Zealand. It has the potential to link with data collected by the NHWT and other similar groups to track graduates after they leave medical school. This will allow further exploration of factors influencing career choice and destination, and continued data collection on the location and types of their clinical experience. Linking the MSOD with the forthcoming national medical registration system has the potential to identify specialty, practice location and changes in patterns of medical practice. In addition, the MSOD project offers a facility for conducting targeted substudies of specific policy or research questions, not unlike other well known longitudinal studies such as the 45 and Up Study. ${ }^{15}$ The project has access to $100 \%$ of the relevant student doctor population, and to date has achieved a student participation rate of 


\section{EDITORIALS}

around $95 \%$, providing a high-quality sampling frame on which to base any empirical study.

MDANZ considers MSOD an essential resource and is fully committed to its success - but is this sufficient to ensure its sustainability? Given the tyranny of distance, the process of bringing diverse groups together has required fostering trust and collegiality among all players around a shared project goal, in order to minimise competition and apprehension. Moreover, longitudinal studies have a long lead time before results become apparent, and convincing funders that outputs will justify the time and resources needed requires good ongoing communication and strong partnership arrangements. The Australian Government Department of Health and Ageing has provided crucial financial support that has produced a solid foundation without which the MSOD project would not have progressed.

Several factors have been built into the project with a view to ensuring its sustainability. The database has not been produced by any one individual, university or workforce organisation. Instead, a collective approach that reflects all parties as equal partners is led by the MDANZ steering and management group. The process is underpinned by project officers who liaise with stakeholders. Project objectives, processes and desired outcomes are shared by all parties, and stakeholders are regularly engaged in full and open discussion of any likely sticking points, including ethics, ownership of data, roles and responsibilities. Agreed principles (such as simplicity, necessity, consistency, objectivity, sufficiency and relevance) guide the data collection process and support the intended outcomes. While all medical schools share a belief that the total good is more valuable than the sum of the parts, there is ample opportunity within the MSOD and Longitudinal Tracking Project to conduct rigorous substudies, either by individual medical schools or in partnership with others.

Sound medical workforce policy decisions and reforms cannot be made in the absence of quality longitudinal data. The MSOD project is unique, well established and running effectively. With the continued and sustained commitment of MDANZ and the Department of Health and Ageing, the full potential of this resource as a valuable platform for informing a more coordinated approach to medical workforce planning will be realised.

\section{Competing interests}

David Prideaux is a member of the Management Committee of MSOD and has received travel assistance to attend meetings. Nicholas Glasgow is employed by the Australian National University as Dean of Medicine and Health Sciences and Dean of the Medical School.

\section{Author details}

John S Humphreys, BA(Hons), DipEd, PhD, Professor of Rural Health Research $^{1}$

David Prideaux, BA(Hons), MEd, PhD, Deputy Dean and Professor of Medical Education ${ }^{2}$

Justin J Beilby, MB BS, MD, FRACGP, Executive Dean ${ }^{3}$

Nicholas J Glasgow, MB ChB, MD, FRACGP, Dean, Medicine and

Health Sciences ${ }^{4}$

1 School of Rural Health, Monash University, Bendigo, VIC.

2 School of Medicine, Flinders University, Adelaide, SA.

3 Faculty of Health Sciences, University of Adelaide, Adelaide, SA.

4 Medical School, Australian National University, Canberra, ACT.

Correspondence: john.humphreys@med.monash.edu.au

\section{References}

1 Marchal B, Kegels G. Health workforce imbalances in times of globalization: brain drain or professional mobility? Int J Health Plann Manage 2003; 18 Suppl 1: S89-S101.

2 Zurn P, Dal Poz MR, Stilwell B, Adams O. Imbalance in the health workforce. Hum Resour Health 2004; 2: 13.

3 Rabinowitz HK, Veloski JJ, Aber RC, et al. A statewide system to track medical students' careers: the Pennsylvania model. Acad Med 1999; 74 (1 Suppl): S112-S118.

4 Lambert TW, Goldacre MJ, Edwards C, Parkhouse J. Career preferences of doctors who qualified in the United Kingdom in 1993 compared with those of doctors qualifying in 1974, 1977, 1980, and 1983. BMJ 1996; 313 : 19-24.

5 Geyman JP, Hart LG, Norris TE, et al. Educating generalist physicians for rural practice: how are we doing? J Rural Health 2000; 16: 56-80.

6 Rabinowitz HK. A program to recruit and educate medical students to practice family medicine in underserved areas. JAMA 1983; 249: 10381041.

7 Rabinowitz HK. Evaluation of a selective medical school admissions policy to increase the number of family physicians in rural and underserved areas. N Engl J Med 1988; 319: 480-486.

8 Rabinowitz HK. Recruitment, retention, and follow-up of graduates of a program to increase the number of family physicians in rural and underserved areas. N Engl J Med 1993; 328: 934-939.

9 Rabinowitz HK, Diamond JJ, Markham FW, Hazelwood CE. A program to increase the number of family physicians in rural and underserved areas: impact after 22 years. JAMA 1999; 281: 255-260.

10 Wilkinson D, Laven G, Pratt N, Beilby J. Impact of undergraduate and postgraduate rural training, and medical school entry criteria on rural practice among Australian general practitioners: national study of 2414 doctors. Med Educ 2003; 37: 809-814.

11 Commonwealth Department of Health and Family Services. The current state of undergraduate medical education for rural practice: report of the mid-term review of the General Practice Rural Incentives Program's rural undergraduate component. Canberra: Commonwealth of Australia, 1998.

12 Humphreys JS, Mara P, Jones M. The RUSC program review - enhanced sustainability, accountability and program integration. Canberra: Department of Health and Aged Care, 2000.

13 Medical Training Board. The future of the medical workforce: first annual report November 2007 - December 2008. Wellington: Ministry of Health, 2009.

14 Medical Deans Australia and New Zealand. Medical Schools Outcomes Database (MSOD) and Longitudinal Tracking Project Newsletter. 2009 Jun; (2): 1. http://www.medicaldeans.org.au/MSOD_Webpages/ Docs\%20for\%20Website/Reports\%20\&\%20Newsletters/MSOD\%20 Newsletter\%20lssue\%202.pdf (accessed Aug 2009).

15 Banks E, Redman S, Jorm L, et al; 45 and Up Study Collaborators. Cohort profile: the 45 and Up Study. Int J Epidemiol 2008; 37: 941-947. 